\title{
CRÍTICA BIBLIOGRÁFICA
}

\author{
LITERATURA DE VIAGEM
}

Um livro de Mário Graciotti sôbre Portugal (1)

Portugal, estreita faixa de terra do Ocidente europeu que o mar alarga, debruçado graciosamente sôbre o Atlântico, é, sem dúvida, um dos países mais deleitáveis do Velho Mundo. $\mathrm{E}^{\prime}$ um pedaço de terra onde o céu parece estar mais perto. $\mathrm{O}$ seu clima é de uma benignidade e doçura extremas. Para o estrangeiro, sobretudo para nós brasileiros, tudo, ali, é uma tentadora atração. Portugal parece estar sempre em primavera. Comunicativo e acolhedor, repleto das mais aprazíveis quintas de recreio e vales amenos, profundamente humanizado, proporciona aos que o visitam recepção digna de uma antiga e leal эmizade.

Espraiando-se, ondeante, Portugal, porta aberta para o continente europeu, assume aspectos maravilhosos de forma e de côr, incomparáveis, mercê das excepcionais condições de clima, de relêvo e da tradicional labuta do seu povo imbuído de sentimento que afeiçoa os mais circunspectos. Em Portugal tudo tem interêsse turístico - as cidades e os campos. E' um "pedaço do céu" onde nos sentimos como se estivéssemos em nossa própria casa, em família, e onde se tem a exata experiência da sadia hospitalidade.

Portugal deve ao Atlântico a clemência e a meiguice do seu clima, sem invernos rigorosos nem estios abafadicos. Há, é, claro, diferenças climáticas entre o norte e sul, entre a costa e o interior. Pode dizer-se, de maneira geral, que o clima português é mais benigno no sul e no litoral, mais rigoroso no norte e no interior. Graças ao condicionalismo geográfico favorável (diversidade geológica, regime de ventos, variedade de relêvo, grau de humidade e abundância ou escassez de cursos de água), as paisagens vegetal e animal são variadíssimas. Acrescente-se a êsses fatôres positivos a atividade do litoral, e compreenderemos melhor a multiplicidade de gêneros de vida da população portuguêsa. O mar que banha as costas, pouco

(1). - Portugal. Crônidas de viagem para aduitos e crianças. Editôra Clube do Livro Ltda. 418 págs. São Paulo, 1957. 
profundo e influenciado pela ação benéfica da Corrente do Gôlfo, oferece condições excepcionais para o desenvolviment? de certas espécies marinhas em cardumes densos, magnificamente representados pela sardinha e pelo atum. "Essa ambicionada riqueza piscosa chamou para a costa o elemento humano do interior, transformando agricultores em pescadores, marinheiros e comerciantes, que no século XV haveriam de conquistar para o mundo Ocidental o Atlântico ignoto. Sôbre êsse país delicioso e mágico, "jardim dos amores à beira-mar plantado", a conceituada editôra Clube do Livro, desta caṕital, prosseguindo no seu trabalho de divulgação cultural, acaba de nos brindar com mais uma formosa crônica de viagem de Mário Graciotti. O livro, cheio de beleza e de comovido amor à terra dos nossos maiores, onde crepita e reluz uma alta flama de ternura, intitula-se - Portugal, crônicas de viagem para adultos e críanças.

Trata-se de alentado volume de 418 páginas escritas em rico papel "couchê" importado, com 280 fotografias das mais características sôbre cidades e monumentos históricos, e 84 desenhos originais alusivos ao texto.

Merece relêvo a opulenta apresentação gráfica da obra. Compondo-a e imprimindo-a com apuro e requinte, o Clube do Livro honra as artes gráficas brasileiras. O cuidado pôsto na ilustração fala por si do carinho e esmêro com que a obra foi concebida e realizada. Por isso, e pela serenidade e equilíbrio das opiniões e ensinamentos que expende, merece, além de ser divulgada, figurar em tôdas as bibliotecas do gênero. Basta nomear-se o autor para se ter o elogio da obra, profusamente ilustrada, com sobrecapa a côres e uma série de expressivas vinhetas do conhecido pintor Vicente Di Grado.

Quer pela agilidade da prosa, quer pela feliz apropriação dos temas e riqueza de informes, "Portugal" justifica o conceito em que é tido pela crítica falada e escrita. Mário Graciotti está de parabéns. Trata-se de um escritor de reconhecido talento e - o que se nos afigura importante - cheio de entusiasmo pelas coisas superiores e belas. E note-se: o que mais nos maravilha é o carinho e a ternura com que êle sabe compreender e amar Portugal. Benquerendo a poética e acolhedora terra lusitana, Mário Graciotti, filho de pais italianos, dá uma sadia lição moral a certos portuguêses "aburguesados" no estrangeiro.

Laureado pela Academia Brasileira de Letras, que em 1950 line concedeu o ambicionado prêmio "Carlos de Laet", pelo seu 
belo livro Europa Tranquiila, Mário Graciotti, que guarda da profissão a agilidade de raciocínio e a facilidade de redigir qualidades completadas pelo gôsto das informações - vê consagrada a sua obra, em matéria de literatura de viagem, com "Portugal", livro que se lê com prazer, proveito e sem fadiga. Por que não dizê-lo - de um folêgo.

O principal intento do autor foi escrever uma obra de fundo histórico ao alcance de tôdas as inteligências - "crônicas de viagem para adultos e çrianças". Ésse objetivo foi plenamente alcançado. E não é preciso mais para recomendálo. Livro de divulgação destinado a tôdas as idades. Com êle, o autor ascende ao estrelato. Nele Portugal encontra novo espaço para crescer. O consagrado escritor presta, assim, um serviço inestimável à Comunidade lusíada, justificando, pler.amente, pelo volume e brilho de sua produção literária, a aureola que merecidamente ostenta nas letras e nos círculos editoriais brasileiros.

Amigo sincero de Portugal e admirador dos seus feitos e magnanimidades, Mário Graciotti, que no verão de 1951 visitou a bela e boa terra, compôs com arte e tngênho um autêntico poema lírico ao "jardim da Europa", cantando-lhe as belø:zas e virtudes, com lealdade e sentimento.

Pela emoção e subtileza artística, o autor é um autêntico "português" - lusíada de 24 quilates. Na sua obra escritz com paixão sente-se o vibrar de uma alma "excelentemente portuguêsa".

A obra dá-nos uma idéia muito clara do que foi e do que é Portugal. Nela se encontra aquilo que se procura. O trabalho, de real mérito, é o fruto da permanência do escritor em Portugal e de contínuo e estafante estudo de gabinete, fato demonstrativo da honestidade intelectual de Mário Graciotti.

O livro, sugestivo roteiro traçado como diário de viagem, apresenta-nos os seguintes capítulos: 5 mil fardos de algodão: crônicas do mar distante; o senhor Equador; os rochedos de São Pedro e São Paulo; susto a bordo; ilha da Grã-Canária; nas alturas de Marrocos; bom-dia Portugal; Lisboa - feira popular; Lisboa - Estoril africano; Lisboa - alecrim doirado; Lisboa - Alvalade; Lisboa - caldeirada; Lisboa - os Jerônimos; Lisboa - um punhado de flores; Mafra - 7.525 portas e janelas; Ericeira; Setúbal; o infante D. Henrique - nasce um mundo novo; o infante D. Henrique - Ceuta, a porta da Africa; o infante D. Henrique - a caravela, o domínio do Atlântico; Sintra; Caldas da Rainha; Aljubarrota; Fátima; 
-.. Inês de Castro; Buçaco - no Castelo Real; Aveiro; Vilia Nova de Gaia; Pôrto - passeio noturno; Pôrto - vinho verde; Pôrto - a tôrre dos clérigos; Braga; Monte Sameiro; Viana do Castelo; Guimarães - nos tempos de Viriato; Guimarães - o Castelo de Mumadona; Leixões; D. Manuel, o venturoso - "Minha terra tem palmeiras"; despedida.

E' uma obra cheia de beleza e de fé, em cujos capítulos palpita a graça idílica de um dos povos mais líricos da terra. O livro, todo êle, revela uma alma sensível e grandiosa impregnada de lusitanidade. Obra de leitura atraentíssima, é sobreInaneira valiosa, pois raros são os aspectos sociais e morais da vid portuguêsa que escaparam ao estudo objetivo do autor que nos ajuda, assim, a compreender e amar mais ainda o nosso Portugal.

Seria ocioso tentar salientar aqui, nas estreitas balizas de uma nota bibliográfica, o valor particular de cada crônica do livro. A acolhida dispensada a "Portugal" fala por si melhor que qualquer outro comentário.

O infante D. Henrique, no entanto, apaixonou o autor. Não admira. Este capítulo, realmente, merece destaque. Outrossim, é digno de alguns apontamentos.

Trata-se de uma época em que Portugal é o bandeirante do mar ignoto. O pequeno país atlântico, situado numa encruzilhada de dois mundos - a Europa do Norte e o bloco da orla mediterrânea -, apertado contra o mar por um vizinho ciumento e absorvente, encontrou no Oceano o seu melhor amigo. As suas privilegiadas condições geográficas, aliadas à sagacidade da sua gente, explicam, em boa parte, tôda a sua fortuna $e$ prestígio. Rotas de comércio que partiam do Mar do Norte, do Báltico e do Mediterrâneo, convergiam, regularmente, para os portos portuguêses que se ofereciam à navegação e às trocas mercantis (2). No século XIII, Portugal já possuia um verdadeiro gênero de vida nacional - o comércio marítimo à distância assente na agricultura (3), caracterizado pela sucessiva va-

\footnotetext{
(2). - A partir do século XIII, o Mediterrâneo passou a utilizar a rota marítima da Flandres que deslocou o eixo comercial do Reno para o Atlântico europeu. A famosa rota terrestre dos Alipes, descendo do Reno para o Mar do Norte, de onde se distribuia para a Liga Hanseática, que servia o Báltico, principiza a minguar.

(3). $\rightarrow$ Cf. Cortesão, J. - "Os factores democráticos na formação de Portugal", in História do Regimem Republicano em Portugal v. I, pág. 41, Lisboa, 1930; Sérgio, A. - Histónia de Portugal, págs. 23 e seg., Col. Labor, 1929; História de Portugal, v. I, Introdução Geográfica, Lisboa; Em tôrno da designação de monarquia agrária dada à primeira época da nossa história. Lisboa', 1941 .
} 
lorização das classes populares e conseqüente expansão ultramarina (4). O movimento demográfico português, que se seguiu à fundação da monarquia, utilizara a costa e explorara o mar. Os dois coordenados movimentos de conquista e valorização da terra criaram o gênero de vida e prepararam o advento da Nação.

Pelas condições do seu comércio à distância, e pela privilegiada posição geográfica, Portugal era chamado a intervir na rota marítima italiana da Flandres. A costa portuguêsa era uma excelente escala das trocas mediterrâneas, de um lado, e dos entrepostos do Mar do Norte, de outro. Para ela afluiam mercadores e marinheiros de tôda a parte - italianos, catalães, marselheses, flamengos, alemães e inglêses.

Resolvido a tirar partido das circunstâncias favoráveis, advindas dêsse magnífico nó de rotas comerciais, Portugal incrementou, cada vez mais, as suas relações navais e mercantis com - Mar do Norte, com o Marrocos atlântico e com o Mediterrâneo afro-europeu (5). As crescentes exigências de abastecimento e de transporte seriam, assim, o maior incentivo ao trato à distância, ao desenvolvimento técnico, às construções navais, enfim, à acumulação social de riqueza.

Em Portugal tudo se conjugava no sentido de tornar viável a gloriosa obra de expansão com que sonhavam as classes avançadas do Ocidente cristão. A reconquista e a independência nacional eram problemas resolvidos. Todos estavam dispostos a. enfrentar, lúcida e corajosamente, incentivados por uma car. rada de razões, o Atlântico tenebroso e ignoto.

Obcecados e perseguidos por esta idéia, é que Portugal, fazendo convergir para o mesmo ponto de mira as aspirações da Coroa, do clero, da burguesia e da nobreza, e instigado pelos sagazes mercadores do Mar do Norte e da Europa Central, investiu, com redobrado vigor, contra Ceuta, miradouro do Es-

\footnotetext{
(4). - São desencontradas as opinióes a respeito do gênero đe vida português na Idade Média. Gama Barros (História da Administração Pública em Portugal nos séculos $X I I$ a $X V, 11$ vs, Lisboa, s. d.), Alberto Sampaio (Estudos histórioos e econômicos, v. I, Pôrto, 1926) e Lúcio de Azevedo (Épocas de Portungal econômico, Lisboa, 1947; "Organização Econômísa", in História de Portugal, t. II, Ed. Portucalense, Lisboa, 1929), mais de uma vez afirmaram que Portugal, durante a primeira dinastia, foi um país lavrador. Preferimos as hipóteses de Jaime Cortesão e A. Sérgio, que apontam a atividade marítima, com base na agricultura, como traços fundamentais da vida portuguêsa na Idade Média.

(5). - Os Livros das Chancelarias (IV de D. Dinis, e III e IV de Afonso IV), guardados no Arquivo Nacional da Tôrre do Tombo, em Lisboa, ministram valiosos informes para um estudo dessa natureza.
} 
treito e um dos estratégicos têrmos das rotas transaarianas do ouro sudanês. Era o primeiro passo para a conquista do Atlântico. Salto inédito na história do mundo. Significativa marcha para o futuro da civilização cristã . Revelação de grandes e fecundas consequiências. Ponto de partida para a integração da civilização européia na civilização mundial.

A conquista oceânica data do século XV - século moderno, século português. Até então, o grande e importante Oceano constituira uma barreira à expansão civilizadora dos povos europeus. As tendências de universalização do Ocidente cristão viram-se, durante milênios, sustadas pelo obstáculo atlântico - fatalismo geográfico. O grande acontecimento do mundo moderno, como já o notou Magalhães Godinho (6), consistiu em derrubar essa barreira quase intransponível.

A expansão da civilização ocidental cristã coincide com êsse importantíssimo e repercussivo acontecimento. O Atlântico, uma vez integrado na navegação sistemática, tornou-se logo a mais fecunda via de contacto intercontinental. Disciplinado o mar desconhecido, o Mediterrâneo ítalo-muçulmano foi perdendo, dia a dia, sua tradicional função histórica. A primasia passou para o novo Oceano, onde o organismo europeu encontrou a seiva vivificadora indispensável ao seu crescimento.

Distanciando-se dos povos que até então haviam tentado a devassa do Atlântico, os portuguêses encetaram uma tarefa que modificou profundamente a fisionomia do mundo. O fato é inteiramente novo. Nada tem com o movimento ítalo-catalão dos séculos XIII e XIV, que malogrou. Os navios, que tant.) impressionaram Graciotti, são atlânticos. A navegação é à vela. Barcos a remos não ousam navegar no mar largo. As pesadas e dispendiosas galeras venezianas não se atreviam a entrar pelo Atlântico a dentro. Até o século XV, o Oceano é pràticamente ignorado. Apenas experiências em tôrno das ilhas. Nada mais que isso. Não admira, pois, que êle não apareça nia cartografia medieval. Todos os esforços haviam sido, até então, frustrados. Por isso é deveras escasso o acêrvo de informes geográficos. Além do Bojador, nada se conhece. Além das ihhas nada se sabe. Tudo figura no romance geográfico. Tôdas as tentativas de conquista oceânica, anteriores às henriquinas, malograram. Tôdas as experiências abortaram. O insucesso

(6). - "Création et Dynamisme économique du Monde Atlantique", 1420-1670, in Annales d'hist., pág. 33, janeiro-março, 1950; A expansão qưatrocentista portứưuêsa, pág. 45, Lisboa, 1944. 
conduzia, assim, à consolidação das tradicionais rotas marítimas de comércio.

Ao declinar o século XIII (1291), dois genoveses, os irmãos Vivaldi, partindo de sua terra transpuseram Gibraltar e penetraram no Atlântico. Até hoje, entretanto, nada se sabe do desfêcho da audaciosa emprêsa. Teodésio d'Oria, que financiou o empreendimento, organizou novas viagens à procura dos "náufragos", mas sem resultados. E' de se crer que tivessem alcançado as Canárias, para onde se dirigiam em busca de mão de obra escrava reclamada pelo açúcar do Mediterrâneo Ocidental, particularmente de Valência (7).

Em 1312, o genovês Lancelotto Mallocelli redescobriu as Canárias, apoderando-se da ilha que recebeu o seu nome Lançarote (8). A partir de então, italianos, portuguêses, andaluzes, catalães e maiorquinos, organizaram novas investidas, com o objetivo do saque. Os informes, porém, são os mais desencontrados. Cada qual procura reivindicar para a sua agremiação o redescobrimento das desejadas ilhas - mercado de escravos.

A colonização das Canárias, no entanto, data do século XIV (1402-1405). Jéan de Béthencourt e Godifer de la Salle, a serviço de Espanha, partindo de La Rochelle, alcançaram as procuradas ilhas onde estabeleceram uma colônia de normandos (9) .

Desde então as contradições luso-castelhanas se sucederam (10). Uma coisa, entretanto, se nos afigura certa: a iniciação

(7). - Cf. Roncière, $\mathrm{Ch}$, de $\mathrm{La}-\mathrm{La}$ découverte de l'Afrique au moyen âge, t. II, págs. 4 e seg., Cairo, 1926; Caddeo, R. - Le navigazioni atlantiche di Alvise da Ca da Mosto, pág. 64, Milão, 1928; Machado, Franco - "O conhecimento dos arquipélagos atlânticos no século XIV, in Históría da Exp̣ansão Portưuêesa no Mưndo, v. I, págs. 269 e seg., Lisboa, 1937

(8) . - Blanco, R. Roman - "Anchieta não é português", in Revista de História, pág. 147, n.o 15. S. Paulo, 1953; Godechot, J. - Histoire de l'Atlantique, pág. 37, Paris, 1947.

(9). - Cf. Margry, P. - La conquéte et les conquerants de Iles Camiries. Noutvelles recherches sur Jean IV de Bêthencourt et Godifer de la Salle, le vrai manuscrit $d u$ Canarien. Paris, 1896.

(10). - Vejam-se os estudos - Machado, F. - "Descobrimentos e colonização do Arquipélago da Madeira. A questão das Canárias", in História da Expansão Portugưuêsa no Mundo, v. I, págs. 275 e seg., Lisboa, 1937; Boccacio, Giovanni —Wotícia de uma expedição às ilhas Canárias que partiu de Lisboa em $1 .^{\circ}$ de Juiho de 1341 e regressou à mesma cidade em Novembro dêste ano", in J. M. da Silva Marques - Descobrimentos portuguêses. Docutmentos para a sua históriał v. I, págs. 77 e segs. Versão portuguêsa do texto latino de J. J. da Costa de Macedo, ibidem, págs. 80 e segs., Lisboa, 1944; "Carta del-rel D. Afonso IV ao Papa Clemente VI", ibidem, págs. 88 e segs.; Frei- 
colonial espanhola nas Canárias é obra estrangeira. Só após a conquista cristã de Granada (1492) é que a Espanha lançou os primeiros fundamentos da sua expansão atlântica. Antes disso, a navegação castelhana se circunscreveu às ilhas. Nada mais. A expansão espanhola é tardia, em relação à portuguêsa. Quando Castela ultimou a reconquista, Portugal já tinha organizado as rotas da Mina e de Arguim em sólidas linhas, preparando-se para dobrar o Cabo e disputar o fndico afro-asiático ao Islão Oriental.

Por isso Mário Graciotti enamorou-se da emprêsa henriquina, que deu ao mundo o desejado espaço para crescer.

\section{MANUEL NUNES DIAS}

Assistente da Cadeira de História da Civil zação Moderna e Contemporânea da Universidade de São Paulo.

tas, Jordão - "A carta de D. Afonso IV ao Papa Clemente VI", in Diário de Notícias de 16 de julho. Lisboa, 1917; Baião, A. - "Os meus pareceres a respeito das reproduçōes da carta de Afonso IV", in Boletim da 2a. Classe da Academia das Ciências, t. XI, págs. 71 e segs.; Azevedo, Pedro de - "O traslado da carta de D. Afonso IV ao Papa Clemente VI sôbre as Canárias". Ibidem, t. XI, pág. 66 . 